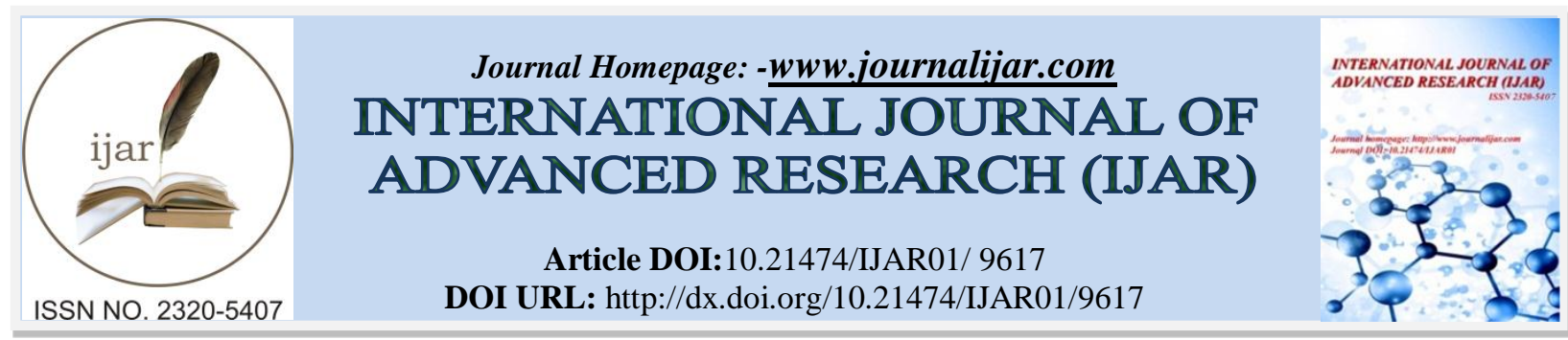

RESEARCH ARTICLE

\title{
DOES ADDITION OF TAMOXIFEN TO BICALUTAMIDE TREATMENT HAS A ROLE IN DECREASING INCIDENCE OF BREAST PAIN AND GYNECOMASTIA IN CASES OF CARCINOMA PROSTATE?
}

Dr. Neel Patel.

Senior Resident,Department of Urology,Aurangabad.

\section{Manuscript Info \\ Manuscript History \\ Received: 20 June 2019 \\ Final Accepted: 22 July 2019 \\ Published: August 2019}

Abstract

\section{Introduction:-}

Bicalutamide150 mg monotherapy is an accepted treatment option for prostate cancer patients without metastatic disease who wish to avoid the adverse effects of surgical or medical castration. ${ }^{1,2}$ Bicalutamide 150 mg monotherapy has been investigated in prostate cancer as either alone or as adjuvant to radical prostatectomy or radiotherapy. It showed a significant decrease in the risk of prostate-specific antigen (PSA) doubling, objective disease progression, and development of bone metastases for patients receiving bicalutamide $150 \mathrm{mg}^{3}$

A treatment option in patients with early prostate cancer(PCa) is radical prostatectomy (RP) and most men undergoingthis surgical treatment have an excellent outcome. However, a significant proportion of patients can experience diseaserecurrence. Prostate specific antigen (PSA)progression is the earliest evidence of persistent or recurrentdisease after primary therapy with curative intent.

In previously untreated patients with nonmetastaticPCa150 mg bicalutamidemonotherapy has been shown to beequivalent to castration in terms of the survival rate at amedian followup of 6.3 years, offering quality of life (QOL)advantages with respect to sexual interest and physical capacity. The value of adding $150 \mathrm{mg}$ bicalutamide daily tostandard care for early PCa is being investigated in thebicalutamide early prostate cancer (EPC) program, which isthe largest international clinical trial of early PCa therapy todate. ${ }^{4}$ The EPC program is ongoing and data on the effect oftreatment on mortality are still missing. Followup will providefurther clarification on the role of bicalutamide in thissetting.In the EPC program the incidence of gynecomastia andbreast pain is $68.3 \%$ and $73.6 \%$, respectively, with symptomsdeveloping in the majority of patients within the first 6 to 9 months of bicalutamide therapy.

Objective of the study was to look for the effects of Bicalutamide on symptoms of gynecomastia and breast pain in our patients and role of addition of Tamoxifen to standard bicalutamide treatment in decreasing the symptoms.

Patient recruitment. This single center, randomized trialwas done between January 2016 and February 2018 at Pramukh Swami Medical College, Karamsad. Thestudy population consisted of men with histologically confirmedprostate cancer without distant metastases (T1-T3, any N, M0) and no evidence of current gynecomastia orbreast pain.

All patients had received RP with or without anerve sparing (NS) procedure as primary therapy. 
Exclusion criteria were previous hormonal therapy forPCa, metastatic disease, evidence of biochemical relapse afterRP, any comorbid condition that could contraindicate trialdrugs, or hematological (hemoglobin $10 \mathrm{gm} / \mathrm{dl}$ or less, whiteblood count less than 3,000/ul and platelet count less than100,000/ul), renal (creatinine $2.2 \mathrm{ng} / \mathrm{nl}$ or greater) or liver(transaminase and bilirubin $50 \%$ of normal or greater) dysfunction.

Study design. Treatment was assigned on a randomizedbasis according to a 1:1 ratio. Stratification factors were diseasestage (T1-T2 vs T3), lymphnode involvement $\left(\mathrm{N}_{-}\right.$vs $\left.\mathrm{N}_{+} \mathrm{vsN}_{\mathrm{x}}\right)$, Gleason score (lessthan 7 vs 7 or greater) and PSA (less than $10 \mathrm{vs} 10 \mathrm{ng} / \mathrm{ml}$ orgreater). All randomly assigned patients were included inefficacy and safety analyses.

All patients were divided into 2 groups. Patients in Group 1 received only $150 \mathrm{mg}$ bicalutamide daily with placebo.Group 2 patients were treated with $150 \mathrm{mg}$ bicalutamide daily and $20 \mathrm{mg}$ tamoxifen daily for 24 weeks.

Oncological follow up: Physical examination, hematologyand serum biochemistry evaluations, including total PSA,were performed every 3 months. Radiological assessments, i.e.computerized tomography, bone scan, abdominal ultrasonographyand chest $\mathrm{x}$-ray, were performed when disease progressionwas suspected based on PSA. PSA progression was definedas 2 consecutive PSA increases (greater than $0.04 \mathrm{ng} / \mathrm{ml}$ ).

Gynecomastia/breast pain assessment : Calipers were usedto measure gynecomastia. The severity of gynecomastia wasscored based on the largest diameter, including grade 1-2 orless, grade 2-between 2 and 4, grade 3-between 4 and 6 , and grade 4 -greater than $6 \mathrm{~cm}$. Breast pain was evaluatedvia direct patient questioning at each visit. It was arbitrarilyscored according to severity as none, mild, moderate or severe.

Gynecomastia and breast pain were evaluated monthly.

\section{Statistical methods:-}

The chi-square and Fisher's exacttests were used to compare groups in respect to the incidenceof gynecomastia, breast pain between groups 1 and 2 .

Overall 40 patients were randomized and included in theanalysis. Patients and disease characteristics were well balancedamong treatment groups (table 1). Minimum followupwas 12 months (median 24, range 13 to 30) in all patients.

Table 1:-Patient Demographics

\begin{tabular}{|l|l|l|}
\hline & Group 1 & Group 2 \\
\hline No of Patients & 20 & 20 \\
\hline Age & & \\
Mean & 68.25 & 65.75 \\
Range & $59-76$ & $58-72$ \\
\hline $\begin{array}{l}\text { No. Stage } \\
\text { T1-T2 }\end{array}$ & 16 & 15 \\
T3 & 4 & 5 \\
\hline No. of Gleason Score & & \\
Less than 7 & & \\
$>7$ & 10 & 10 \\
& 10 & 10 \\
\hline PSA before RP & & \\
$<10$ & 12 & 13 \\
$>10$ & 8 & 7 \\
\hline Node Status & 14 & 13 \\
N+ & 2 & 4 \\
N- & 4 & 3 \\
Nx & & \\
\hline
\end{tabular}


Efficacy. Figure 1 shows the incidence of grade 3-4 gynecomastiaand moderate-severe breast pain after 6 months ineach group.In group 1, $14(70 \%)$ patients had gynecomastiacompared with $2(10) \%$ in group 2. Thedifference was statistically significant between groups 1 and 2 ( $p$ value 0.0001 ). 15 patients (75\%) in group 1 developed breast pain compared to 3 patients $(15 \%)$ in group 2 which was significant $(\mathrm{p}$ value $=0.00013)$.

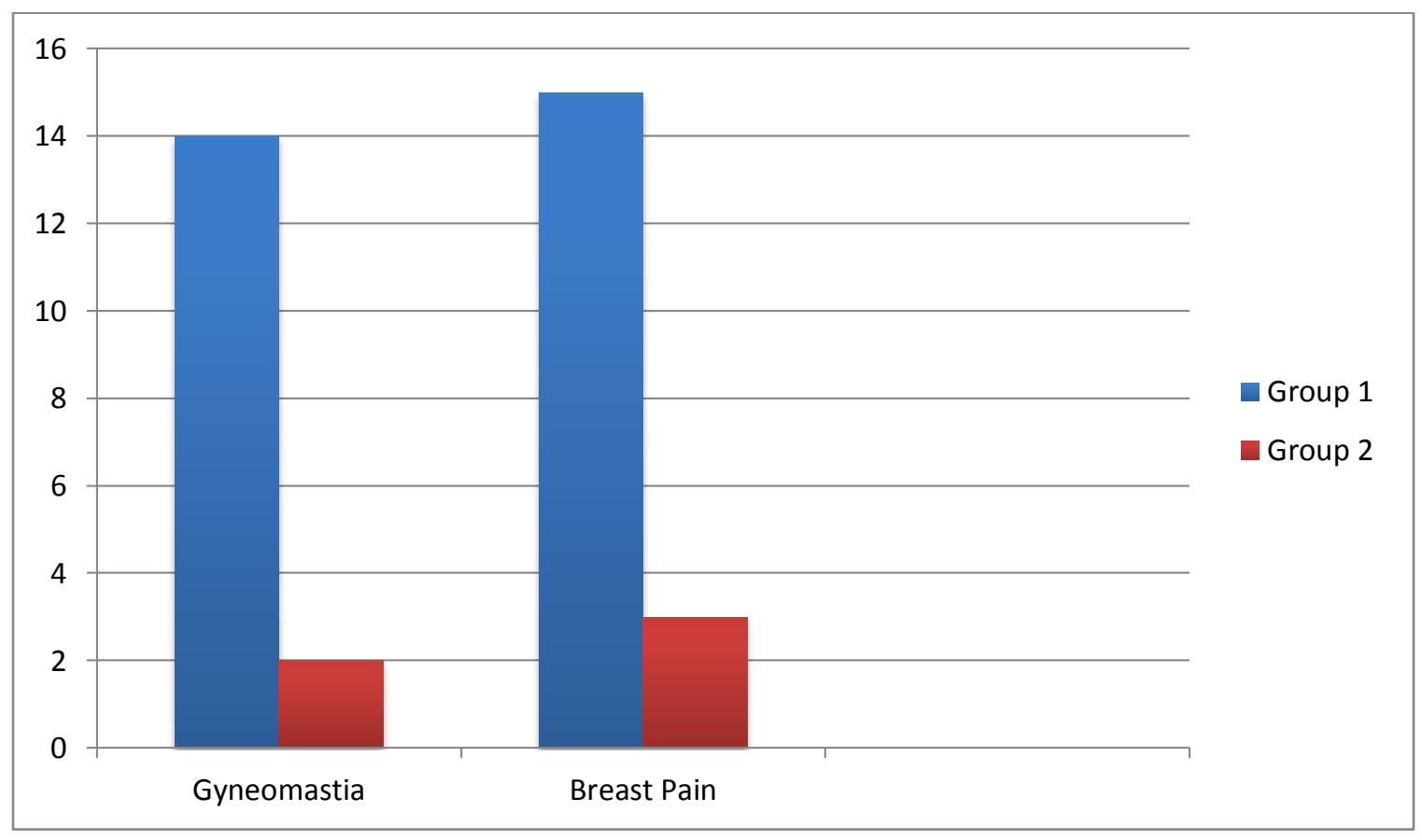

Adverse Events: Overall treatments were well tolerated in both groups. However adverse events were higher in the Group 1 compared to group 2, which indicates that addition of Tamoxifen, do not cause much adverse effects.

\begin{tabular}{|l|l|l|l|l|}
\hline \multirow{2}{*}{ Adverse Events } & Group 1 & \multicolumn{2}{c|}{ Group 2 } \\
\cline { 2 - 5 } & Number of patients & $\%$ & Number of patients & $\%$ \\
\hline Total patients with adverse events & 6 & $30 \%$ & 5 & $25 \%$ \\
\hline Rash & 1 & $5 \%$ & 0 & $0 \%$ \\
\hline Fever & 0 & $0 \%$ & 1 & $5 \%$ \\
\hline Neurologic events & 2 & $10 \%$ & 1 & $5 \%$ \\
\hline Cardiovascular events & 1 & $5 \%$ & 1 & $5 \%$ \\
\hline Respiratory events & 0 & $0 \%$ & 1 & $5 \%$ \\
\hline Intercurrent infections & 1 & $5 \%$ & 1 & $5 \%$ \\
\hline Hot flashes & 1 & $5 \%$ & 0 & $0 \%$ \\
\hline
\end{tabular}

\section{Discussion:-}

Gynecomastiaand breast pain are commonly reported adverseevents of bicalutamidemonotherapy and they may causesome patients to withdraw from treatment. Several interventionshave been used as prevention, including surgery, hormonetherapy and radiation.

Data from old studies of patients with prostate cancer who weretreated with the estrogen antagonist tamoxifenare today supported by recently published trials confirming that hormonaltreatment can be used to restore the balance of estrogenand androgen. Boccardo and Saltzstein et al recently reported 2 randomized trials of the role of tamoxifenand anastrozole for the prevention of gynecomastia andbreast pain.

Bicalutamide $150 \mathrm{mg}$ is generally well tolerated. However,breast pain and gynecomastia occur in a significantproportion of patients and can necessitate treatment discontinuation. 
The mechanisms involved in the development of gynecomastiaduring bicalutamide $150 \mathrm{mg}$ monotherapy are relatedto the hypergonadotropic effects of the drug. Increases intestosterone levels are commonly observed in men receivingantiandrogenmonotherapy and are accompanied by comparableincreases in the level of 17 beta estradiol because of aromatizationof androgens in extragonadal tissues. Estrogensinduce the benign proliferation of male breast glandular tissue, and if proliferation is long standing, irreversible hyalinization and fibrosis may occur.

In a study done by Lorenzo et $\mathrm{al}^{5}$ gynecomastia and breast pain was found in $8 \%$ and $7 \%$ of patients respectively taking $150 \mathrm{mg}$ Bicalutamide treated with Tamoxifen. This is comparable to our study in which we found rate of gynecomastia and breast pain in $10 \%$ and $15 \%$ of patients.

\section{Conclusion:-}

It is clear that bicalutamide-induced gynecomastia and breast pain can be prevented by the concurrent administrationof tamoxifen. This beneficial effect can be achieved without alteringPSA response rates and safety and without compromisingsexual functioning.

\section{Funding:}

None

\section{Conflict of interest:}

None declared

\section{Ethical approval:}

Not required

\section{Reference:-}

1. Iversen P, Tyrrell CJ, Kaisary AV, et al: Casodex (bicalutamide) 150-mg monotherapy compared with castration in patients with previously untreated nonmetastatic prostate cancer: Results from two multicenter randomized trials at a median follow-up of 4 years. Urology 51:389-396, 1998.

2. Iversen P, Tyrrell CJ, Kaisary AV, et al: Bicalutamidemonotherapy compared with castration in patients with nonmetastatic locally advanced prostate cancer: 6.3 years of followup. J Urol 164:1579-1582, 2000.

3. See WA, Wirth M, McLeod DG, et al:Bicalutamide as immediate therapy, either aloneor as adjuvant to standard care of patients withlocalized or locally advanced prostate cancer:First analysis of the Early Prostate Cancer Program. J Urol 168:429-435, 2002.

4. Wirth, M. P., See, W. A., McLeod, D. G., Iversen, P., Morris, T.and Carroll, K.: Bicalutamide $150 \mathrm{mg}$ in addition to standardcare in patients with localized or locally advanced prostatecancer: results from the second analysis of early prostate cancerprogram at median followup of 5.4 years. J Urol, 172: 1865,2004

5. Lorenzo, Giuseppe Di, SistoPerdonà, Sabino De Placido, Massimo D'Armiento, Antonio Gallo, Rocco Damiano, DomenicoPingitore, Luigi Gallo, Marco De Sio, and Riccardo Autorino. "Gynecomastia And Breast Pain Induced By Adjuvant Therapy With Bicalutamide After Radical Prostatectomy In Patients With Prostate Cancer: The Role Of Tamoxifen And Radiotherapy." Journal of Urology 174, no. 6 (2005): 2197-203. doi:10.1097/01.ju.0000181824.28382.5c. 